\title{
EDUCAÇÃO, DIVERSIDADE NUM MUNDO DE PÓS-VERDADE
}

\author{
EDUCACION, DIVERSIDAD EN UN MUNDO POST-VERDAD
}

EDUCATION, DIVERSITY IN A POST-TRUTH WORLD

\author{
Maria Regina MOMESSO ${ }^{1}$ \\ Solange Aparecida de SOUZA MONTEIRO²
}

RESUMO: Vive-se a era da pós-verdade, cujo conceituação é de grande complexidade, pois a "pós-verdade" não se constitui apenas numa mentira, ou meia verdade, ou convicção. A verdade é um efeito discursivo. Esse fenômeno implica na maioria dos casos na prevalência de uma "verdade" sustentada por um raciocínio axiológico e patêmico. Estudar e problematizar a pós-verdade dentro do campo educacional se faz urgente, em especial, quando um dos deveres da escola são o acolhimento e a compreensão da diversidade humana. Assentados nos estudos de autores como Foucault, Angenot, Emediato, Boudon, partimos da premissa que a pós-verdade acentua-se na sociedade brasileira causando a indisponibilidade ao diálogo, assim, a maior parte das pessoas tendem a tratar as informações como verdadeiras só àquelas que confirmem suas crenças em detrimento daquelas que as invalidam. Cabe a todos sabermos problematizar o caráter retórico da percepção da pós-verdade, olhando para suas derivas, suas dispersões, no sentido de compreendermos como lidamos com aquilo que lemos, vemos, sentimos e agimos.

PALAVRAS-CHAVE: Educação escolar. Diversidade humana. Pós-Verdade.

RESUMEN: La era de la posverdad vive, cuya conceptualización es de gran complejidad, porque la "posverdad" no es sólo una mentira, o la mitad verdadera, o convicción. La verdad es un efecto discursivo. Este fenómeno implica en la mayoría de los casos la prevalencia de una "verdad" sostenida por un razonamiento axiológico y patético. Es urgente estudiar y problematizar la posverdad dentro del ámbito educativo, especialmente cuando uno de los deberes de la escuela es la recepción y comprensión de la diversidad humana. Basándonos en los estudios de autores como Foucault, Angenot, Emediato, Boudon, suponemos que la posverdad se acentúa en la sociedad brasileña causando indisponibilidad al diálogo, por lo tanto, la mayoría de la gente tiende a tratar la información como sólo aquellos que confirman sus creencias en detrimento de aquellos que las invalidan. Depende de todos saber cómo problematizar el carácter retórico de la percepción post-verdad, mirando sus derivas, sus dispersiones, para entender cómo lidiamos con lo que leemos, vemos, sentimos y actuamos.

PALABRAS CLAVE: Educación escolar. Diversidad humana. Después de la verdad.

${ }^{1}$ Universidade Estadual Paulista (UNESP), Araraquara - SP- Brasil. Docente do Programa de Pós-Graduação em Educação Sexual, e no PPG Educação Escolar da Unesp, Araraquara/SP. Docente FEB-CTI-Unesp em Bauru/SP. Linguista e líder do Grupo de Pesquisa Gesteld (www.gesteld.com) ORCID: <https://orcid.org/00000001-7342-577X>. E-mail: regina.momesso@unesp.br

2 Universidade Estadual Paulista (UNESP), Araraquara - SP- Brasil. Doutoranda em Educação Escolar. Pedagoga no Instituto Federal de Educação Ciência e Tecnologia de São Paulo (IFSP), Araraquara - SP - Brasil. Mestra em Processos de Ensino, Aprendizagem e Inovação. ORCID: 〈http://orcid.org/0000-0002-1640-0266>. E-mail: solmonteiro@ifsp.edu.br 
ABSTRACT: The era of post-truth lives, whose conceptualization is of great complexity, because the "post-truth" is not just a lie, or half true, or conviction. Truth is a discursive effect. This phenomenon implies in most cases the prevalence of a "truth" sustained by an axiological and pathetic reasoning. Studying and problematizing post-truth within the educational field is urgent, especially when one of the school's duties is the reception and understanding of human diversity. Based on the studies of authors such as Foucault, Angenot, Emediato, Boudon, we assume that the post-truth is accentuated in Brazilian society causing unavailability to dialogue, thus, most people tend to treat information as only those who confirm their beliefs to the detriment of those who invalidate them. It is up to all to know how to problematize the rhetorical character of post-truth perception, looking at its drifts, its dispersions, in order to understand how we deal with what we read, see, feel and act.

KEYWORDS: School education. Human diversity. Post-Truth.

O século XXI emerge sob égide da complexidade das relações humanas e das mudanças civilizacionais. A complexidade e as transformações atingem a todos de forma implacável, em especial no que tange a educação; ao acolhimento e a compreensão da diversidade humana em seus vários âmbitos, soma-se a isso o modo como às pessoas interpretam a "verdade" do que ouvem, veem, leem, sentem ou a expressam.

As sociedades contemporâneas parecem viver num paradoxo constante: por um lado temos o neoliberalismo tentando impor-se e, por outro, o clamor da discussão de temas como o da diversidade humana e identitária, reivindicada por diversos movimentos/manifestações constantes em busca do reconhecimento das próprias especificidades (TOSI, 2010).

"Et verbum caro factum est et habitavit in nobis"3 (JOÃO, 1-14). Assim como no preceito bíblico, compreendemos que tudo se inicia pelo verbo, aqui entendido como o discurso. Tudo começa pela/na linguagem, pelo/no discurso, a construção de uma casa começa pela expressão de um sonho, de uma vontade que depois se transforma em um projeto de casa para se chegar ao objeto casa.

Foucault (2005) deixa de entender a palavra/discurso como um conjunto de signos que remetem ou são representações das coisas apenas, sua compreensão de discurso é mais complexa, pois o compreende como as práticas que criam essas coisas. Logo, “discurso é um conjunto de enunciados que, além de designar as coisas, produzem-nas, e devem ser vistos como práticas que formam sistematicamente os objetos de que falam" (FOUCAULT, 2005, p. 33). São João no texto bíblico já metaforizava o sentido do verbo/palavra: E o verbo se fez carne; e a palavra tornou-se corpo; e a palavra fez-se real/concreta.

3 "E o Verbo se fez carne e habitou entre nós" São João, 1 - Bíblia Católica Online Leia mais em: https://www.bibliacatolica.com.br/biblia-ave-maria-vs-vulgata-latina/sao-joao/1/ 
Acerca da palavra/discurso na antiguidade clássica, Platão toma-a como phármakon, que pode ser veneno, remédio ou cosmético. Por isso phármakon é um termo contraditório, conforme Derrida (1991, p.41) seu sentido é impossível de ser fixado num dos contrários sem a presença do outro. $\mathrm{O}$ veneno pode ser remédio e vice-versa; a droga pode ser cura/medicina e vice versa; a vida pode ser morte e vice-versa. Desta feita, Platão no Fedro, confirma como remédio (a dialética) e como veneno (a escrita, graphé). De modo que a proximidade de Sócrates com o phármakon possui esse caráter contraditório, que lhe concede tanto a possibilidade quanto a impossibilidade de ser o que é. Por isso, deve-se estar cuidadoso e atento com a utilização de phármakon.

Essa palavra/discurso construiu e continuando construindo o mundo em que vivemos e sua interpretação nos faz entendê-la, senti-la, experimentá-la por meio de uma ou mais verdades.

Se dermos um pequeno passeio pela literatura ou filosofia, pode-se perceber que a palavra/discurso foi utilizada para produzir um tipo de verdade. Só a título de exemplificação: no classicismo a verdade era universal, filtrava-se na razão, no equilíbrio, na proporção, na objetividade, na transparência.

No Barroco a verdade constrói-se por meio da palavra/discurso controversa, dúbia, para alguns um silogismo aristotélico, em que a relação de forças entre os afetos e a razão produz "a verdade" como uma pérola irregular.

Já no Arcadismo a produção da verdade volta-se novamente para a razão, que se assenta nos ideais iluministas, aos moldes kantianos de que o iluminismo era a capacidade de servir-se da sua própria razão.

Parece que o discurso/palavra "verdade" vem se construindo em práticas discursivas que ora predomina-se na razão e ora na emoção. Foucault (2011, p. 316) insiste em afirmar que "não há instauração da verdade sem uma posição essencial da alteridade. A verdade nunca é a mesma”. Só pode haver verdade na forma do outro mundo e da vida outra. O filósofo parecia preconizar o que na contemporaneidade denominamos de pós-verdade.

Segundo o jornal El país o termo post-truth (pós-verdade) foi o destaque do ano 2016 nos Dicionários Oxford, a matéria deste periódico em 17/11/2016 trazia em seu subtítulo: No debate político, o importante não é a verdade, mas ganhar a discussão. Em seguida, Hancock (2016, p. 1) conceitua pós - verdade "como relativo ou referente a circunstâncias nas quais os fatos objetivos são menos influentes na opinião pública do que as emoções e as crenças pessoais".

Passado dois anos, dessa matéria, a afirmação do subtítulo sobre a questão de que no campo político a verdade não era importante, mas sim ganhar a discussão ampliou-se para 
outros campos de atuação da vida comezinha. Ganhar a discussão tornou-se imperativo em muitas áreas, em especial nas redes sociais.

Este texto tem como objetivo refletir sobre a pós-verdade no campo da educação e da diversidade humana. Como podemos educar os homens para a verdade pautada na ética? Como a pós-verdade põe em risco um dos grandes desafios da educação é que o de promover o acolhimento e a compreensão da diversidade humana em seus vários âmbitos, seja dentro ou fora da escola?

\section{Educação e Diversidade humana}

As propostas da Educação brasileira na contemporaneidade colocam em pauta os desafios do século 21: a desigualdade, a falta de acesso à educação para todos, à inclusão e o respeito à diversidade, etc. Argumentam que só a educação integral pode superar o ensino tradicional centrado na transmissão de conhecimentos.

A recente homologação em dezembro de 2018 da Base Nacional Comum Curricular sela essa ideia de educação integral, baseada em três pilares, a saber: a visão do estudante (ele passa a ser protagonista de sua aprendizagem); desenvolvimento pleno e integração curricular.

A BNCC regulamenta quais são as aprendizagens a serem desenvolvidas nas escolas públicas e privadas (Educação Infantil, Ensino Fundamental e Médio) em todo o Brasil, cuja implementação deve se dar até 2020. A orientação tem como premissa maior que uma educação de qualidade é aquela que possa promover a construção de uma sociedade justa, democrática e inclusiva.

Segundo alguns entusiastas da nova BNCC, dentre eles o Instituto Ayrton Senna, afirmam que ela traz inovação quando propõem 10 competências gerais com vistas à promoção de uma nova Escola com as seguintes características: a) socializadora do conhecimento; b) centralizadora da educação no indivíduo, c) processo de Aprendizagem pauta-se no confronto de problemas reais; d) agenciadora de equidade; e) anti-intelectualista; f) pragmática e g) propicia um lugar de aprendizagem democrático.

Dessas 10 competências, duas - a 8 e a 9 -, parecem apontar para a questão do trabalho com a diversidade humana:

8. Conhecer-se, apreciar-se e cuidar de sua saúde física e emocional, compreendendo-se na diversidade humana e reconhecendo suas emoções e as dos outros, com autocrítica e capacidade para lidar com elas.

9. Exercitar a empatia, o diálogo, a resolução de conflitos e a cooperação, fazendo-se respeitar e promovendo o respeito ao outro e aos direitos humanos, com acolhimento e valorização da diversidade de indivíduos e de 
grupos sociais, seus saberes, identidades, culturas e potencialidades, sem preconceitos de qualquer natureza.

Compreende-se que para tratar da diversidade humana de forma integral, contemplando as duas competências gerais, acima citadas, não se pode deixar de pensar numa educação sexual formal.

Nos últimos tempos a educação para a sexualidade humana vem sendo discutida, inclusive na BNCC, na qual a Educação para sexualidade aparece na descrição da área Ciências da Natureza (p. 325), consta que:

Nos anos iniciais, pretende-se que, em continuidade às abordagens na Educação Infantil, as crianças ampliem os seus conhecimentos e apreço pelo seu corpo, identifiquem os cuidados necessários para manutenção da saúde e integridade do organismo e desenvolvam atitudes de respeito e acolhimento pelas diferenças individuais, tanto no que diz respeito à diversidade étnicocultural quanto em relação à inclusão de alunos da educação especial.

Nos anos finais, são abordados temas relacionados à reprodução e à sexualidade humana, assuntos de grande interesse e relevância social nessa faixa etária, assim como são relevantes, também, o conhecimento das condições de saúde, do saneamento básico, da qualidade do ar e das condições nutricionais da população brasileira.

Múltiplos são os elementos necessários ao acolhimento da diferença. E, ainda, a base legal para trabalhar tanto com o tema do corpo, quanto a sexualidade dentro do campo científico precisa ser ajustadas. Advém de um prenuncio destas questões passar pelo crivo e responsabilidade da família e das suas relações com a sociedade, não atrelando o tema apenas na disciplina de Ciências da Natureza.

$\mathrm{Na}$ estrutura da BNCC, os conteúdos do documento estão organizados em disciplinas. Estas são distribuídas ao longo dos anos por "Unidades Temáticas", cada uma dividida em "Objetos de Conhecimento". Estes objetos de conhecimento têm "Habilidades" que devem ser alcançadas pelos estudantes e, é no oitavo ano, que o tema sexualidade aparece na disciplina de Ciências da Natureza.

Na Unidade Temática "Vida e Evolução" há dois objetos de conhecimento: mecanismos reprodutivos e sexualidade (p. 346-347). Dentre as habilidades constam:

- Comparar diferentes processos reprodutivos em plantas e animais em relação aos mecanismos adaptativos e evolutivos;

- Analisar e explicar as transformações que ocorrem na puberdade considerando a atuação dos hormônios sexuais e do sistema nervoso;

- Comparar o modo de ação e a eficácia dos diversos métodos contraceptivos e justificar a necessidade de compartilhar a responsabilidade na escolha e na utilização do método mais adequado à prevenção da gravidez precoce e indesejada e de Infecções Sexualmente Transmissíveis (IST). 
- Identificar os principais sintomas, modos de transmissão e tratamento de algumas ISTs (com ênfase na AIDS), e discutir estratégias e métodos de prevenção.

Destaca-se que a compreensão do corpo, sua constituição, modificações, deveriam ir além de saúde sexual e reprodutiva, da seleção de argumentos que evidenciem as múltiplas dimensões da sexualidade humana (biológica, sociocultural, afetiva e ética) e, portanto, sua diversidade.

Neste contexto, há no próprio documento oficial que orienta o que deve constar no currículo escolar, o suporte para que a sexualidade seja compreendida a partir da diversidade. Incluir as dimensões socioculturais, afetivas e éticas, junto às biológicas, é apresentar o quão diversos somos, em termos de espécie. Também é nossa condição de assegurar que através do conhecimento possamos não só evidenciar estas dimensões, mas aprender a conviver com elas e respeitá-las.

Desenvolver o conhecimento de si e do outro, o cuidado de si em/com relação a outrem, aprender e promover atitudes de respeito e acolhimento pelas diferenças individuais, à diversidade étnico-cultural numa sociedade líquido moderna em que os valores são fluídos, torna-se uma tarefa árdua e complexa.

Sabe-se que na prática efetiva o respeito, a ética, o acolhimento, a garantia dos direitos sociais pela diversidade humana não acontecem como prescrito na constituição brasileira: “Todos são iguais perante a lei”. A esse respeito Gomes (2006), afirma:

\begin{abstract}
A luta pelos direitos às diferenças sempre esteve presente na história da humanidade e sempre esteve relacionada com a luta dos grupos e movimentos que colocaram e continuam colocando em xeque um determinado tipo de poder, um determinado padrão de homem, de política, de religião, de arte, de cultura. Também sempre esteve próxima às diferentes respostas do poder em relação às demandas dos ditos diferentes. Respostas que, muitas vezes, resultaram em formas violentas e excludentes de se tratar o outro: a colonização, inquisição, cruzadas, escravidão, nazismo.
\end{abstract}

Diante da argumentação de Gomes (2006) deve-se ter o cuidado de educar para a cultura da paz, do autoconhecimento e do conhecimento do outro, para poder evitar respostas equivocadas que resultem no ódio, na desavença e, portanto, na violência e na exclusão ou do diferente ou do mais desfavorecido.

A BNCC apresenta-se resistente à diversidade sexual e de gênero na escola, de maneira que suas recomendações mostram retrocessos na discussão desta temática quando cotejada àquelas apresentas nos PCN. Sendo assim, os apontamentos de Palma et al. (2015) no que concerne às concessões realizadas pelos $\mathrm{PCN}$ para a temática não representaram em si 
estratégias de enfrentamentos e questionamentos, mas configuraram-se em silenciamentos da diversidade sexual e de gênero que germinavam naquele período.

Foi em meio a este movimento, que surgiram comemorações a cerca da supressão do debate sobre gênero e sexualidade, inclusive em reportagens, no dia subsequente à divulgação da $3^{\mathrm{a}}$ versão da BNCC, em manchete que anunciava Bancada evangélica festeja a retirada de questão de gênero da Base Curricular" (BALLOUSSIER, 2017). A comoção se refletiu na esfera da sociedade civil e mundial.

Para Feitosa (2017) aponta que existem divergências de interpretações até mesmo entre os diferentes fact-checkers. O autor enfatiza para que:

\footnotetext{
"nunca deixar de nos perguntar criticamente quem são e como o fazem, estes que assumiram para si a tarefa de controlar a veracidade dos discursos dos outros. Avaliar continuamente não só os discursos, mas também os avaliadores e os próprios instrumentos de avaliação, é a tarefa política constante daqueles que ainda tem respeito pela liberdade e pelo pensamento".
}

Isso compreende também o aprendizado da autoavaliação, pois a pós-verdade, percebida neste contexto não como a "não-verdade", mas como a "verdade pluralizada e sob constante tematização", FEITOSA(2017), estabelecendo continua e progressivamente maiores interpretações.

\section{A Educação para a Diversidade Humana diante dos jogos de verdade na contemporaneidade}

Angenot (2008) em seu livro "Dialogues de sourds: traité de rhétorique antilogique", reflete sobre nossos discursos sociais desde o político até o discurso doméstico da contemporaneidade, os quais para o autor são sempre pautados numa retórica antilógica. Apesar de todos os humanos argumentarem constantemente em todas as circunstâncias de produção discursiva, segundo Angenot (2008) é muito raro persuadirem-se reciprocamente, ou seja, não há diálogo, não se admite as opiniões contrárias, não há argumentação, por isso se estaria na era do diálogo entre os surdos. Para Angenot, os discursos na atualidade pautamse em controvérsias (filosóficas, religiosas, políticas etc.), as quais evocam um autoritarismo da interpretação.

$\mathrm{Na}$ era da pós-verdade parece acentuar-se a indisponibilidade ao diálogo, as pessoas tendem a tratar as informações predispostas a lerem-nas de forma a encontrar "a verdade" que lhes convém aos seus afetos, crenças e valores. Logo, a verdade é vislumbrada por uma ótica da retórica antilógica, sofística, em que o que importa é vencer o debate, mesmo que não se tenha uma apreensão cautelosa dessa "verdade". O sujeito na contemporaneidade não está 
disposto em ver o diferente, o contrário, nem de compreender se esta "verdade" é verificável, ou mera suposição, ou comprovadamente mentirosa. O que importa é se aquela "pós-verdade" é a que lhe convém e esta de acordo com suas convicções.

Há que se compreender que a pós-verdade não se resume apenas a uma fake-news, ou uma mentira, ou uma meia verdade. A fake news, a mentira ou a meia verdade são facetas da pós-verdade. A definição de pós-verdade é muito mais complexa, pois envolve a falta de equilíbrio entre razão e emoção, entre ethos e pathos, cuja falta abre espaço para as convicções. Assim, a problemática da pós-verdade envolve várias facetas: a verdade/a mentira; a difusão de fake-news, que pode ou não conter uma parcela factual; as convicções/a persuasão, em que as convicções estabelecem um tipo de raciocínio que não permite compreender a dinâmica de validade das verdades de cada lado da questão instalada como pós-verdade.

Angenot (2008) ao tratar da convicção política coloca que está obedece às mesmas estruturas de funcionamento das convicções religiosas e outras.

Boundon (2017) aponta para a era da racionalidade instrumental, axiológica e patêmica de cada sujeito, ou seja, essa racionalidade ancora-se numa visão utilitarista sem outros filtros de validade das verdades no mundo, o que importa são as convicções, os valores, há um desejo de verdade que se confunde com a própria verdade, o que predisporia o sujeito a aderir a pós-verdade, mesmo que esta seja mentira, ou meia verdade, ou frágeis. Essa pós-verdade revela as convicções, esta de acordo com os valores e crenças de determinados indivíduos. Isto explicaria o desinteresse em buscar descobrir a veridicção factual e as verdades, pois aos sujeitos é mais interessante a manutenção de suas convicções. Desta feita, a checagem dos fatos, fundamentos e fontes não é importante.

A esse respeito Emediato (2016, p. 17) afirma que as verdades, por serem relativas dependem essencialmente de seus domínios de validação, por exemplo, no domínio científico o critério é científico espistemológico; no jurídico, os critérios são deontológicos; no religioso são epifânicos; no político são ideológicos, logo, esses domínios de validação tornam as verdades discursivas e retóricas. Assim, depende-se do critério de validação a quem esta submetida esta pós-verdade.

Emediato (2016, p. 16) ainda sustenta que "as verdades são construções sociais e humanas, podem ser justificadas, relativizadas, validadas, falseadas e hierarquizadas".

Se se entender a pós-verdade como discursiva, acorda-se também com Foucault (2002) que afirma que a materialidade discursiva produz verdade, portanto, a verdade seria um efeito discursivo que fabrica as realidades, sejam elas sociais, pessoais, culturais, científicas, etc. Cada realidade produz um regime de verdade, em dada época, conforme cada cultura e etc. Os 
regimes de verdade instalam e constituem a cultura de uma época, os quais trazem em sua base diferentes formas de exclusão, juntamente com as ironias e contradições que permeiam esses processos, mostrando separações paradoxais porque produzem ao mesmo tempo, resistências. São porosas, misturadas, complexas.

Ao pensar na diversidade humana pertencente ao mundo do discurso social, a pósverdade presente nesse discurso pode implicar em vários conflitos e polêmicas de toda ordem. E, sabendo-se, que a pós-verdade constitui-se em processo retórico antilógico assentado nas paixões, valores, crenças dos diferentes sujeitos produtores desse discurso. Nem sempre essa "pós-verdade" se faz de forma consciente e intencional, com as novas tecnologias ela toma dimensões mais complexas, em que o sujeito pode apenas aderi-la por pura convicção, por esta agradar-lhe às suas paixões e interesses.

As principais características marcantes da pós-verdade ampara-se na aceleração (por exemplo, o imediatismo da internet, tudo em tempo real, pode dificultar a apreensão cuidadosa dos fatos e esta pode ser superficial ou automatizada); a retórica icônica (os discursos por se apresentarem em blocos e em grandes quantidades exigem uma leitura pulular, rápida e facilmente esquecida, sendo feita sempre olhando de forma generalizada e de uma só vez); possui esquemas de ação e protocolos de funcionamento (envolvem caráter cognitivo das convicções pré-programadas, as quais determinam estados de pensamentos e, consequentemente, ações imediatas).

Pode-se observar essas características na matéria jornalística da revista Exame de 20/11/2019, toma-se como exemplo a manchete "Damares cria canal para denunciar professores contra a família". Esse canal estaria sendo criado em função de um acontecimento ocorrido numa escola do distrito federal, na qual um professor de ensino fundamental, $6^{\circ}$ ano, teria solicitado a sua turma que fizesse uma redação sobre sexo oral e anal.

Quais efeitos de verdade essa manchete pode criar?

Dependendo dos critérios de validação de verdade, de ética, do modo como se lê e como se vê a questão da educação sexual dentro da escola poderia se ter algumas construções de efeitos de verdade. Algumas proposições:

$1^{\circ}$ ) Os professores não devem trabalhar a sexualidade na escola por estarem despreparados. Escola é para conteúdos técnicos, sexualidade é assunto familiar. Portanto, precisam ser vigiados e denunciados.

$2^{\circ}$ ) Os professores devem trabalhar a sexualidade na escola, dentro de uma educação formal, ética e pedagógica adequada às condições de cada realidade escolar. Um caso fora 
desse padrão deve ser tratado dentro das instâncias legais já existentes, sem a necessidade da criação de um canal de denúncia.

Essa manchete e a repercussão dessa pós-verdade, certamente, gerara polêmica e, na grande parte dos casos, uma verdade tenderá a prevalecer.

Qual o papel da educação num mundo de pós verdades? Como trabalhar a diversidade humana num tabuleiro de jogos de verdade?

Entende-se que o papel do educador dentro de tabuleiro é o mesmo do intelectual colocado por Foucault (1999, p. 151):

\begin{abstract}
O que um intelectual pode oferecer é fornecer os instrumentos de análise, e é este hoje, essencialmente, o papel do historiador. Trata-se, com efeito, de ter do presente uma percepção densa, de longo alcance que permita localizar onde estão os pontos frágeis, onde estão os pontos fortes a que estão ligados os poderes (...). Em outros termos, fazer um sumário topográfico e geológico da batalha... Eis o papel do intelectual. Mas de maneira alguma dizer: eis o que vocês devem fazer.
\end{abstract}

Cabe a cada educador estudar seu momento presente, problematizando-o. Sabendo que toda e qualquer problematização é processual, é indispensável para a formação humana, não é encontrar respostas, mas sim elaborar questionamentos, é fazer a genealogia do sujeito no caso. Portanto, envolve pensar transversalmente, observar as regularidades $\mathrm{e}$ as descontinuidades das práticas discursivas e não discursivas, implicar-se no processo de pensamento e, por fim, identificar as variáveis que constitui a problemática.

Entender que no lugar de um educador deve existir o máximo de isenção possível, de que embora implicados no processo, deve-se estar num lugar não do certo ou do errado, da verdade universal. Mas, sim no lugar do observador que tem a capacidade de ver as derivas, as margens, as bordas.

Não é o educador que diz a "verdade", que "conduz", mas é o sujeito que provoca a inquietação, a transformação, a dúvida, a busca de cada um em perceber o momento presente de forma densa, de localizar onde estão os pontos frágeis e fortes que estão imbricados nos jogos de verdade.

Esse deveria ser o papel não só do educador, mas de qualquer sujeito consigo mesmo: Como interpreto as informações, as verdades que chegam até mim? Quais critérios de validação utilizo para compreender determinada verdade?

\title{
REFERÊNCIAS
}

BALLOUSSIER, A. Bancada evangélica celebra retirada de questão de gênero de base curricular. Disponível em: . Acesso em: nov. 2019. 
BOUDON, R. Crer e saber: pensar o político, o moral e o religioso. Tradução Fernando Santos. São Paulo: Ed. Unesp, 2017

BRASIL. Ministério da Educação. Base Nacional Comum Curricular (1 ${ }^{\text {a }}$ versão). Brasília, DF, 2015. 302p.

BRASIL. Ministério da Educação. Base Nacional Comum Curricular ( $2^{\mathbf{a}}$ versão). Brasília, DF, 2016. 652p. BRASIL. Ministério da Educação. Base Nacional Comum Curricular ( $3^{\mathrm{a}}$ versão - abril de 2017). Brasília, DF, 2017a. 396p.

BRASIL. Ministério da Educação. Base Nacional Comum Curricular ( $3^{\text {a }}$ versão revista dezembro de 2017). Brasília, DF, 2017b. 472p.

DERRIDA, J. A Farmácia de Platão. Trad. Rogério Costa. São Paulo: Iluminuras, 1991.

EMEDIATO, W. Dimensões e face da mentira no discurso político. In: EMEDIATO, Wander (Org.). Análises do Discurso Político. Belo Horizonte: NDA/FALE, 2016.

FEITOSA, C. Pós-verdade e política. Revista Cult. 19 jul. 2017. Disponível em: . Acesso em: 17 nov. 2019.

FOUCAULT, M. A coragem da verdade. São Paulo: Martins Fontes, 2011.

FOUCAULT, M. A arqueologia do Saber. $7^{\text {a }}$ Ed. RJ: Forense Universitária, 2005, p.55

FOUCAULT, M. A verdade e as formas jurídicas. Tradução Roberto de Melo Machado e Eduardo Jardim Moraes et al. Rio de Janeiro: NAU Editora, 2002.

FOUCAULT, M. Em defesa da sociedade. (E. Brandão, Trad.). São Paulo: Martins Fontes, 1999.

GOMES, N. L. Educação e Diversidade Cultural: refletindo sobre as diferentes presenças na escola. Disponível em: http://www.mulheresnegras.org. Acesso em: 18 nov. 2019.

HANCOCK, J. Dicionário Oxford dedica sua palavra do ano, 'pós-verdade', a Trump e Brexit. In: EL PAÍS Internacional. Disponível em:

https://brasil.elpais.com/brasil/2016/11/16/internacional/1479308638_931299.html. Acesso em: 16 nov. 2019.

JOÃO, S. In: BIBLÍA CATÓLICA ONLINE. São João, 1-14. Disponível em https://www.bibliacatolica.com.br/biblia-ave-maria-vs-vulgata-latina/sao-joao/1/. Acesso em: 16/nov/2019.

PALMA, Y. A. et al. Parâmetros Curriculares Nacionais: um estudo sobre orientação sexual, gênero e escola no Brasil. Trends in Psychology/Temas em Psicologia, Ribeirão Preto, v. 23, n. 3, p. 727-738, 2015.

PLATÃO. Diálogos. Trad. Carlos Alberto Nunes. Belém: UFPA, 2003.

TOSI, G. Verbete Igualdade. In: BARRETO, V. P; CULLETON, A. (org.). Dicionário de Filosofia Política. São Leopoldo: Editora Unisinos, 2010, p. 267 


\section{Como referenciar este artigo}

MOMESSO, M. R.; MONTEIRO, S. A. de S. Educação, diversidade num mundo de pósverdade. Doxa: Rev. Bras. Psico. e Educ., Araraquara, v. 21, n. 1, p. 170-181, jan./jun. 2019. e-ISSN: 2594-8385. DOI: https://doi.org/10.30715/doxa.v21i1.13200

Submetido em: 05/11/2018

Revisões requeridas: $22 / 12 / 2018$

Aprovado em: 01/01/2019

Publicado em: 01/02/2019 